\title{
Interactive comment on "Effects of vegetation and soil on evapotranspiration, flow regime, and basin storage in three nearby catchments in northeast Japan" by Shoji Noguchi et al.
}

\section{T. de Boer-Euser (Referee)}

t.euser@tudelft.nl

Received and published: 20 January 2017

The manuscript contains the description of a variety of measurements regarding vegetation (number of tree stands, tree diameter, sap wood area), soil properties (soil depth, pore sizes and hydraulic conductivity) and hydrological fluxes (precipitation and discharge). Based on these measurements the authors aim to link soil and vegetation characteristics to the hydrological behaviour of the catchment. I think that these kinds of measurements are important to increase our understanding of the hydrological functioning of catchments and that analyses based on measurement campaigns should be published. However, the results should be presented in a consistent way and relations between variables should be analysed carefully. 
At the moment the manuscript is rather a presentation of measured data instead of an analysis of measurement results. In addition, the descriptions for different variables are not used in a consistent way. Below I have indicated some aspects which might help the authors to deepen their analysis and increase the value of the manuscript.

\section{General comments:}

Relation between variables The different measured categories of variables (i.e. vegetation, soil properties and hydrological behaviour) are presented separately. As the purpose of the manuscript is not only to present these variables, but to investigate the influence of vegetation and soil on the hydrological behaviour, it would be helpful to add some graphs in which these variables are plotted together.

Presentation of results The authors have presented a large amount of valuable data. However, I think that a different form of presentation can make the data more clear and interesting. For example, some paragraphs contain a lot of numbers, which might be more suitable to present in a table (e.g. P3L1-5) or even on a map (e.g. P6L6-14). In addition, I think that Table 2 can be replaced by a plot of a flow duration curve, maybe together with a plot of the hydrograph and measured preciptiation; this probably gives a clearer overview of the flow regime of the catchment. Further, it would be helpful for the reader to give a clear overview (maybe in a table) of the data collected for this study and the data used from other measurement campaigns, both with the period used.

Effect on evapotranspiration One of the aims of the manuscript is to investigate the influence on evapotranspiration. However, the calculation of evapotranspiration is based on strong assumptions and only presented as six monthly values for the entire measurement period. I think that these data are not sufficient to investigate the influence on evapotranspiration. What could improve the comparison is to actually present the transpiration that was calculated (P3L29), to present

Printer-friendly version

Discussion paper 
more details about the ratios mentioned in P8L5-6 and to present an estimate for potential evaporation.

Effect on basin storage Another aim of the manuscript is to investigate the effect on basin storage. However, it is very unclear how basin storage is defined. The term would suggest it refers to the total storage capacity in the catchment; however, the soil water storage is often a bit higher, so the basin storage probably represents something else. Further, it is unclear whether basin storage is the actual amount of stored water (at which location?), a storage capacity, or even a flux (maybe ground water recharge?). On P5L1 it seems that again a different definition of storage is used. I think that the amount of (active) storage (capacity) in a catchment is very relevant, but different terms should be used in a consistent way.

Conclusions A conclusion section is missing, this again makes the manuscript more a description of data than an analysis of the influence of the measured variables on each other.

\section{Specific comments:}

The abstract contains too much detailed information and misses a clear conclusion regarding the influence of vegetation and soil on evaporation, discharge and storage as promised in the title.

The terms used to classify runoff (plentiful, ordinary, low, scanty) are not very common terms and might seem a bit vague and arbitrary to the reader. Therefore, they are especially not very suitable to use in the abstract.

Printer-friendly version

Discussion paper

Hydrology describes a cycle, this implies that there are no yields nor losses. Especially the term 'loss' is very confusing as the authors seem to use it for both interception evaporation as for groundwater recharge. 
P2L3, this seems a very quick conclusion based on the previous sentence.

P3L2, which ratio is referred to here, that of slope to which other variable?

Why is the period for the analysis in section 2.1 different from that in 2.4 ?

2.3, choose one of the two: soil storage or soil water storage.

2.3, do the soil depth measurements represent the distance between the soil surface and the bedrock or to another impermeable layer?

2.3, I would use the same units (i.e. or $\mathrm{mm}$, or $\mathrm{cm}$ ) in the entire manuscript and especially within a table (Table 1), this also prevents the need for strange conversion factors as used in Eq.6.

P5L10, the second criteria seems to overrule the first.

2.5.3, this seems a standard method to separate base flow from storm flow, if this is the case, name it like that (with reference), otherwise include a figure explaining the procedure.

P5L29, is evaporation during the runoff event neglected?

P6L18, was the calculated transpiration smaller for catchment \#3 as well?

P7L10, how does the basin storage follow from Figure 7?

P7L10, so the basin storage of \#1 was smaller than that of \#3 and both were smaller than for \#2? If this is the case, it could be made clearer in the text.

Printer-friendly version

P7L20, the previous paragraph seems to present that the basin storage in catchment \#2 is a larger than for \#1 and \#3.

Discussion paper 
P8L5-6, how are these ratios determined? Do they originate from Iwaya et al. (2013)? If so, can they be assumed to be constant in time?

P9L3, this sentence seems to suggest that initial runoff and soil moisture content are basically the same, is this an appropriate assumption? I can imagine that initial runoff is determined by more factors than only soil moisture content.

P9L7, it would be interesting to elaborate this statement a bit further.

F1, some more indications of elevation would be helpful.

F5, consider combining this plot with Figure 4.

F6, for which year did you make this calculation?

F7, the dots for the individual events are difficult to distinguish, maybe try using different colours.

F7, there are four categories in the legend, but only three regression lines are presented. Why are not all categories presented with a regression line?

For investigating the influence of soil and vegetation on storage capacity and hydrological behaviour, these references might be of interest as well:

- Nijzink, R., Hutton, C., Pechlivanidis, I., Capell, R., Arheimer, B., Freer, J., Han, D., Wagener, T., McGuire, K., Savenije, H., and Hrachowitz, M.: The evolution of root-zone moisture capacities after deforestation: a step towards hydrological predictions under change?, Hydrol. Earth Syst. Sci., 20, 47754799, doi:10.5194/hess-20-4775-2016, 2016.

- de Boer-Euser, T., H. K. McMillan, M. Hrachowitz, H. C. Winsemius, and H. H. G. Savenije: Influence of soil and climate on root zone storage capacity, Water Resour. Res., 52, 2009-2024, doi:10.1002/2015WR018115, 2016. 


\section{Technical comments:}

- Be consistent in using figures or words for indicating numbers, especially in P4L12 and P14L4;

- use consistent names or indications for the catchments, e.g. \#1, \#2, \#3; instead of alternating 'catchment no. 1' and 'no. 1 catchment';

- P2L11, this sentence seems a bit strange;

- P2L16, in more detail;

- P2L25, consider using catchment properties or catchment characteristics instead of hydrological factors.

Interactive comment on Hydrol. Earth Syst. Sci. Discuss., doi:10.5194/hess-2016-616, 2016. 